\title{
The NORMAN Association and the European Partnership for Chemicals Risk Assessment (PARC): let's cooperate!
}

Valeria Dulio ${ }^{1 *}$ (D) Jan Koschorreck ${ }^{2 *}$, Bert van Bavel ${ }^{3}$, Paul van den Brink ${ }^{4}$, Juliane Hollender ${ }^{5}$, John Munthe ${ }^{6}$, Martin Schlabach ${ }^{7}$, Reza Aalizadeh ${ }^{11}$, Marlene Agerstrand ${ }^{9}$, Lutz Ahrens ${ }^{10}$, Ian Allan ${ }^{3}$, Nikiforos Alygizakis ${ }^{8,11}$, Damia' Barcelo ${ }^{\prime 12}$, Pernilla Bohlin-Nizzetto ${ }^{7}$, Susanne Boutroup ${ }^{13}$, Werner Brack ${ }^{14,15}$, Adèle Bressy ${ }^{16}$, Jan H. Christensen ${ }^{17}$, Lubos Cirka ${ }^{8}$, Adrian Covaci ${ }^{18}$, Anja Derksen ${ }^{19}$, Geneviève Deviller ${ }^{20}$, Milou M. L. Dingemans ${ }^{21,22}$, Magnus Engwall ${ }^{23,24}$, Despo Fatta-Kassinos ${ }^{25}$, Pablo Gago-Ferrero ${ }^{26}$, Félix Hernández ${ }^{27}$, Dorte Herzke ${ }^{7}$, Klára Hilscherová ${ }^{28}$, Henner Hollert ${ }^{15}$, Marion Junghans ${ }^{29}$, Barbara Kasprzyk-Hordern ${ }^{30}$, Steffen Keiter ${ }^{24}$, Stefan A. E. Kools ${ }^{21}$, Anneli Kruve ${ }^{9}$, Dimitra Lambropoulou ${ }^{31}$, Marja Lamoree ${ }^{32}$, Pim Leonards ${ }^{32}$, Benjamin Lopez ${ }^{33}$, Miren López de Alda ${ }^{12}$, Lian Lundy ${ }^{34,50}$, Jarmila Makovinská3 ${ }^{35}$, Ionan Marigómez ${ }^{36}$, Jonathan W. Martin ${ }^{9}$, Brendan McHugh ${ }^{37}$, Cécile Miège ${ }^{38}$, Simon O'Toole ${ }^{39}$, Noora Perkola ${ }^{40}$, Stefano Polesello ${ }^{41}$, Leo Posthuma ${ }^{42,43}$, Sara Rodriguez-Mozaz ${ }^{26}$, Ivo Roessink ${ }^{4}$, Pawel Rostkowski ${ }^{7}$, Heinz Ruedel ${ }^{44}$, Saer Samanipour ${ }^{45}$, Tobias Schulze ${ }^{14}$, Emma L. Schymanski $^{46}$, Manfred Sengl ${ }^{47}$, Peter Tarábek ${ }^{35}$, Dorien Ten Hulscher ${ }^{48}$, Nikolaos Thomaidis ${ }^{11}$, Anne Togola ${ }^{33}$, Sara Valsecchi ${ }^{41}$, Stefan van Leeuwen ${ }^{4}$, Peter von der Ohe ${ }^{2}$, Katrin Vorkamp ${ }^{49}$, Branislav Vrana ${ }^{28}$ and Jaroslav Slobodnik ${ }^{8^{*}+}$

\begin{abstract}
The Partnership for Chemicals Risk Assessment (PARC) is currently under development as a joint research and innovation programme to strengthen the scientific basis for chemical risk assessment in the EU. The plan is to bring chemical risk assessors and managers together with scientists to accelerate method development and the production of necessary data and knowledge, and to facilitate the transition to next-generation evidence-based risk assessment, a non-toxic environment and the European Green Deal. The NORMAN Network is an independent, well-established and competent network of more than 80 organisations in the field of emerging substances and has enormous potential to contribute to the implementation of the PARC partnership. NORMAN stands ready to provide expert advice to PARC, drawing on its long experience in the development, harmonisation and testing of advanced tools in relation to chemicals of emerging concern and in support of a European Early Warning System to unravel the risks of contaminants of emerging concern (CECs) and close the gap between research and innovation and regulatory processes. In this commentary we highlight the tools developed by NORMAN that we consider most relevant to supporting the
\end{abstract}

\footnotetext{
*Correspondence: valeria.dulio@ineris.fr; jan.koschorreck@uba.de;

slobodnik@ei.sk

${ }^{1}$ INERIS, National Institute for Environment and Industrial Risks, Verneuil

en Halatte, France

${ }^{2}$ UBA, Federal Environment Agency, Dessau-Roßlau, Germany

${ }^{8}$ Environmental Institute, Koš, Slovakia

Full list of author information is available at the end of the article
}

\section{Springer Open}

(c) The Author(s) 2020. This article is licensed under a Creative Commons Attribution 4.0 International License, which permits use, sharing, adaptation, distribution and reproduction in any medium or format, as long as you give appropriate credit to the original author(s) and the source, provide a link to the Creative Commons licence, and indicate if changes were made. The images or other third party material in this article are included in the article's Creative Commons licence, unless indicated otherwise in a credit line to the material. If material is not included in the article's Creative Commons licence and your intended use is not permitted by statutory regulation or exceeds the permitted use, you will need to obtain permission directly from the copyright holder. To view a copy of this licence, visit http://creativeco mmons.org/licenses/by/4.0/. 
PARC initiative: (i) joint data space and cutting-edge research tools for risk assessment of contaminants of emerging concern; (ii) collaborative European framework to improve data quality and comparability; (iii) advanced data analysis tools for a European early warning system and (iv) support to national and European chemical risk assessment thanks to harnessing, combining and sharing evidence and expertise on CECs. By combining the extensive knowledge and experience of the NORMAN network with the financial and policy-related strengths of the PARC initiative, a large step towards the goal of a non-toxic environment can be taken.

Keywords: NORMAN network, Suspect screening, Non-target screening, Contaminants of emerging concern, Environmental monitoring, High-resolution mass spectrometry, Effect-based methods, Chemical risk assessment and prioritisation

\section{Background}

The PARC partnership is currently under development as a joint research and innovation programme to support the European Commission (EC) and national chemical risk assessment and management authorities by providing new evidence and methodologies and promoting their uptake in regulatory processes. This applies to currently recognised as well as potential future contaminants of emerging concern (CECs).

Over the past 15 years, the NORMAN Association has developed a network of expert organisations in the field of CECs in the environment. This effort fits well with the aims and structure of the PARC initiative [1] for a European Partnership for Chemicals Risk Assessment. It is therefore no surprise that NORMAN fully supports the "evolution, not revolution" principle of the PARC initiative, and agrees that existing data and methods should be integrated and further developed without "reinventing the wheel", as we explain in more detail in this paper.

In the PARC partnership, the plan is to join forces with scientists to create the next generation of chemical risk assessment and to facilitate 'The European Green Deal' [2], which includes the sustainable management of chemicals for a non-toxic environment. An essential role of this partnership is to foster better use of existing knowledge and data, and better cooperation and coordination of research on the regulatory needs-all in order to improve risk assessment and management, including the development of an EU early warning system for emerging risks of chemicals in the environment.

The European Commission acknowledges the importance of continuously improving knowledge about the (eco)toxicity of chemicals and of adequately addressing uncertainties regarding exposure to chemicals [3, 4]. Moreover, current regulations are not sufficiently effective to tackle CECs and chemical risks in general, since a holistic view is missing and there are often inconsistencies between different use sectors [5]. The vision for future chemicals policy is that chemicals should be dealt with in an integrated manner in an overarching chemicals policy framework covering all types of chemicals and all uses, beyond the current sector-specific regulations.

It is in this context that the NORMAN network came into existence in 2005 as a project, following a call by the EC (DG Research) aimed at creating a permanent platform to reduce knowledge gaps and better meet the requirements of risk assessors and risk managers concerning CECs [6]. NORMAN is today an independent, self-funded, non-profit, multidisciplinary and multinational association in the field of CECs in the environment, which brings together more than 80 organisations representing various stakeholders, including competent authorities, national reference laboratories, research centres, academia and industry-mostly in Europe, but also in North America and Asia [7].

The missions of NORMAN are to: (i) facilitate a more rapid and wider exchange of data on the identity, occurrence and effects of CECs in water, biota, air, soil and indoor environment; (ii) improve data quality and comparability via validation and harmonisation of common sampling and measurement methods (chemical and biological), and (iii) provide tools for the risk and hazard assessment of CECs [6]. Since the primary objective of the NORMAN Association is to act as a science-topolicy interface, the outcomes of the network's activities are regularly shared with the EC's services including DG Environment, European Chemicals Agency (ECHA), European Environment Agency (EEA), EC Joint Research Centre (JRC), international river commissions, regional sea conventions and national regulatory bodies. Currently, nine national regulatory agencies are members of the NORMAN Association.

The NORMAN Association has considerable-and continuously developing-experience of establishing: (i) a consolidated network of closely cooperating laboratories active in research to support chemical risk assessment and management; (ii) a joint, user-friendly and openaccess data space to share knowledge on CECs in the environment and promote harmonised protocols for data collection and reporting; (iii) a collaborative framework 
to foster validation and harmonisation of measurement methods and monitoring tools; (iv) advanced data analysis tools to deal with less-investigated substances in support of a European early warning system to detect emerging chemical risks to the environment, and (v) a system for harnessing, combining and sharing expertise among research teams, national reference laboratories and environmental agencies in innovative methods in support of chemical risk assessment. So far, NORMAN has been strongly involved in CECs in the fresh water aquatic environment and the associated EU policies. The focus has recently extended beyond fresh water to the indoor, marine, soil and terrestrial environments and water reuse, while the scope of CECs is also expanding to include additional parameters such as antibiotic resistance determinants and microplastics.

In this opinion paper we would like to highlight the tools developed by NORMAN that we consider most relevant to support the PARC initiative.

\section{Joint data space and cutting-edge research tools for risk assessment of contaminants of emerging concern}

NORMAN Database System (NDS): data gathering and data management

Perspective and recommendations

Continue to develop the NORMAN Database System (NDS) as a reference database that brings together, in a single platform, widely differing chemical monitoring data acquired using various techniques and in different matrices, thereby ensuring a harmonised approach for data collection, storage, quality control, curation and exchange among NORMAN members and more widely. Future platform development will be guided by the FAIR principles (Findability, Accessibility, Interoperability, and Reuse of data).

The NDS is complementary to the EC Information Platform for Chemical Monitoring (IPCHEM) $[8,9]$ in harvesting chemical target monitoring data, while at the same time paving the way for the development of a new European infrastructure for handling data coming from innovative methods, such as non-target screening (NTS) and effect-based methods (EBM). It should continue in that role.

\section{Rationale}

The crucial task of gathering and managing environmental CEC exposure data to support chemical risk assessment has been the core activity of the NORMAN Association from its start in 2005.

The current NDS [10] is an open-access platform of interconnected databases able to assist effective and rapid screening and risk assessment of contaminants in the environment.

The unique feature of the NDS is that it provides a comprehensive set of data on CECs together with a range of innovative applications for their hazard and risk assessment. These tools range from physico-chemical properties, use characteristics, mass spectral information, and exposure data from target and non-target screening in all environmental compartments, to ecotoxicity data and in situ bioassay signals reflecting mixture toxicity. The NDS currently consists of 12 modules (Fig. 1), of which eleven (Substance Database (SusDat); Suspect List Exchange (SLE); Chemical Occurrence Data (EMPODAT); Ecotoxicology; Bioassays Monitoring Data; MassBank Europe; Digital Sample Freezing Platform (DSFP); Indoor Environment; Passive Sampling; Substance Factsheets; Prioritisation) are accessible, interlinked and populated with data. The 12th is an antibiotic-resistant bacteria and genes module (ARB\&ARG) that is still under development, while a new module hosting data on microplastics is currently being designed.

A selection of the NDS modules most relevant to PARC is presented below.

\section{NORMAN Substance Database: a common list of substances for harmonised chemical risk assessment Perspectives and recommendations}

Further develop the Substance Database (SusDat) as the cornerstone of a common European platform where information on highly relevant and newly discovered environmental pollutants can be shared in a harmonised format [11].

\section{Rationale}

A common, harmonised list of chemical compounds shared among all parties in research and regulation is one critical requirement for enhanced cooperation among existing regulatory frameworks and shifting towards a "one chemical, one assessment" paradigm. However, current chemicals lists are fragmented collections, with researchers and regulators all using their own lists.

We believe that the combination of NORMAN Suspect List Exchange (SLE) [12] and the merged NORMAN Substances Database [13] of the NDS could be a globally leading model for collaboratively working towards such a list. Numerous organisations, national and international regulatory agencies and research groups from Europe and North America already contribute to this initiative. NORMAN SLE is a platform to share lists of substances potentially responsible for emerging risks to ecosystems and human health. The submitted lists are shared with US EPA CompTox Chemicals Dashboard [14, 15] and PubChem [16, 17] and are published on Zenodo [18]. By 


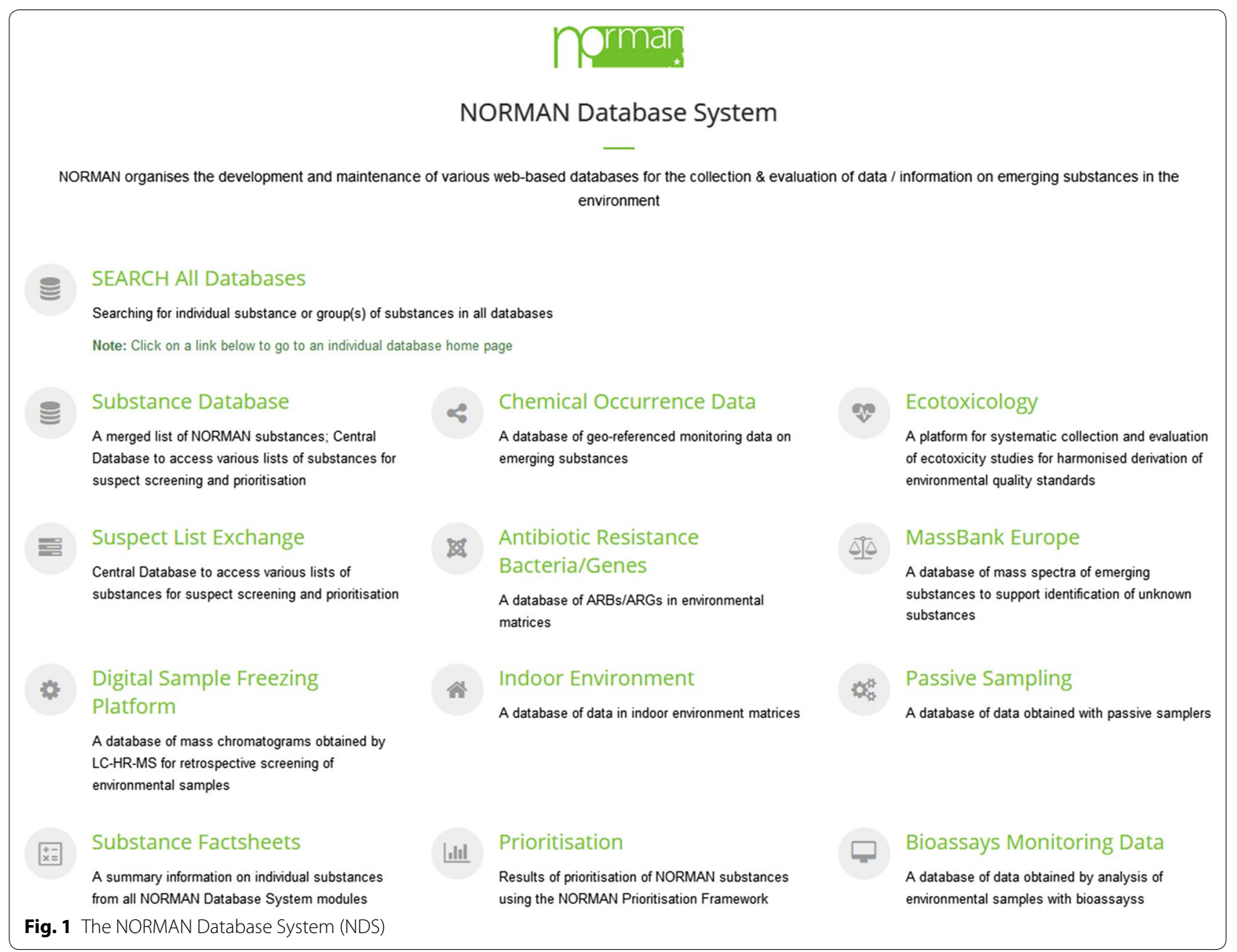

acting as a data collector, the NORMAN SLE has become an important source of specialised research information for major chemical databases such as PubChem and CompTox, beyond the realms and means of individual researchers. In return, the integration of the NORMAN SLE into major chemical databases adds enormous value to the original contributions, offering up new functionality for all parties.

The merged list (without duplicates) is known as NORMAN SusDat [13] - a curated compound database (65,697 compounds as of April 2020), where substances are merged by the Standard InChIKey, which acts as the unique identifier. This is accompanied by other structural information such as CAS numbers and SMILES, as well as physico-chemical properties. SusDat also contains mappings to the equivalent "MS Ready" forms [19], as well as other mass spectrometric information for the identification of compounds with NTS techniques, estimated (in silico) Predicted No-Effect Concentrations (PNECs), and other information required for the prioritisation and risk assessment of substances. Since 2016, SusDat has been used to interlink all NORMAN databases among themselves, as well as the NDS with major external databases.

\section{NORMAN Ecotoxicology Database: a common platform for ecotoxicity assessment Perspectives and recommendations}

Establish a core team of ecotoxicology experts, from EU Member States and globally, using the Ecotoxicology Database as a basis to evaluate the reliability and relevance of ecotoxicity studies and reach consensus on Quality Standards (i.e. PNEC values) for a more harmonised risk assessment of chemicals.

\section{Rationale}

We propose to share the NORMAN Ecotoxicology Database [20] for harmonised ecotoxicity assessment within the PARC partnership. The database provides a transparent tool to guide experts in: (i) the identification of the 
reliable ecotoxicity studies, based on the CRED (Criteria for Reporting and Evaluating ecotoxicity Data) classification system [21]; (ii) the online derivation of a set of quality standards for each matrix and regulatory framework based on selected 'reliable' ecotoxicity studies, using a built-in software tool implementing the requirements of the EC guidelines [22], and (iii) the final selection of a single, common PNEC value, agreed upon as a result of Europe-wide expert consultations.

At present the database comprises, for almost all SusDat substances (i.e.> 65,000), at least one in silico PNEC [23] based on predicted acute effects for each of the three basic trophic levels of the fresh water compartment (fish, daphnia, and algae), which are used when experimental toxicity data are insufficient or not available. In 2019, a semi-automated tool for retrieving experimental (eco) toxicity data from the US EPA ECOTOX Knowledgebase allowed the import of $>125,000$ experimental data on standard (eco)toxicity endpoints for about 5000 SusDat substances in a format compatible with the metadata requirements of the NORMAN Ecotoxicology Database. Additional experimental (eco)toxicity data and threshold values will be retrieved from other databases such as the REACH portal, the ETOX database of the German Federal Environment Agency, as well as existing PNECs and Quality Standards (EQS) from various regulatory sources. The (eco)toxicity threshold values used for chemicals prioritisation are agreed by experts and referred to as 'Lowest PNECs'. These values are generally calculated for the fresh water matrix and then converted to an equivalent PNEC value for marine water, sediment and biota matrices (for example, bioconcentration factors (BCF) are used for conversion to equivalent PNECs for biota).

\section{EMPODAT: a database of target monitoring data Perspectives and recommendations}

Provide a Europe-wide standard for essential quality information (metadata) accompanying chemical analysis results and commonly agreed minimum requirements to allow interoperability of archived monitoring data.

\section{Rationale}

A game changer for next generation chemical risk assessment is a system able to provide comprehensive information on the exposure of humans and the environment to large numbers of chemicals during the entire life cycle of products, including waste and recycled products.

With the EMPODAT database module [24] of the NDS, the NORMAN Association has already established a collaboration with IPCHEM, the official European repository of monitoring data produced by national monitoring programmes and EU-funded research projects in all matrices and compartments. EMPODAT today hosts approximately 10.3 million geo-referenced target monitoring data of more than 3100 substances in water (surface, ground, and waste water), sediment, biota, soil, sewage sludge and air matrices. The data are publicly accessible and provide an overview of benchmark values on the occurrence of contaminants of emerging concern across Europe. From the start, NORMAN has made a great effort to ensure that the data are gathered in a standard format in order to facilitate data comparability and exploitation across Europe and beyond. These spreadsheet-based Data Collection Templates (DCTs) were developed for each of the matrices, and contain information allowing for automated assessment of data quality.

\section{Non-target screening (NTS) tools and Digital Sample Freezing Platform (DSFP) for retrospective suspect screening of environmental contaminants Perspectives and recommendations}

Establish a federated European infrastructure storing raw non-target screening data converted into a common (open) format, designed for retrospective screening.

Establish a central platform/database storing regularly updated information on available data sets Europe-wide and, eventually, at a global scale.

Apply commonly agreed workflow(s) for retrospective analysis to identify and prioritise pollutants frequently detected in environmental samples.

\section{Rationale}

Thanks to NTS techniques it is possible to obtain an overview of human and environmental exposure to thousands of chemicals simultaneously, with a high level of sensitivity and selectivity, including chemicals that have not been identified previously [25]. The NTS workflows (comprising wide-scope target, suspect and non-target screening) based on full scan, high-resolution mass spectrometry (HRMS), developed by NORMAN members, represent the state-of-the-art methods to deal with realworld contaminant mixtures in a more holistic way.

Active since 2013, the NORMAN NTS Working Group has built a strong collaborative infrastructure and developed innovative tools to facilitate exploitation and interpretation of complex data produced by full scan, HRMS methods. NORMAN members have also developed protocols to implement NTS in routine, regulatory applications. Suspect screening of pre-defined lists of tens to tens-of-thousands of known substances in each sample (supported by NORMAN SLE and NORMAN SusDat) is presently the recommended way forward.

In this context the Digital Sample Freezing Platform [26] is a key tool developed by NORMAN to support suspect and non-target screening. This novel technology 
allows the storage of thousands of high-resolution mass spectra (fingerprints) of all chemicals, metabolites and transformation products detected in each of the analysed samples. Thanks to this platform, it is possible for users to search retrospectively for a large number of compounds (e.g. those in SusDat; see above) in all the "digitally frozen" samples stored in the database and obtain reliable qualitative and semi-quantitative data on their occurrence in the investigated samples.

Further key tools, supported by NORMAN and embedded in the NDS, to assist non-target screening, are:

- MassBank Europe, an open-source, open-access database of mass spectra to support higher confidence identification of suspects and non-targets [27, 28]. Based on MassBank Japan, MassBank Europe was founded in 2011, arising from a NORMAN initiative. Today MassBank contains over 80,000 unique mass spectra for $>14,300$ compounds (database release 2020.05 [29]), including mass spectra of tentatively identified compounds. MassBank Europe is a core service for NORMAN as well as for other initiatives such as HBM4EU (Human Biomonitoring for Europe) initiative [30], ELIXIR [31], the German Network for Bioinformatics Infrastructure (de. NBI) [32] and the German National Research Data Infrastructure Initiative for Chemistry (NFDI4Chem) [33];

- A Retention Time Index (RTI) prediction model [34, 35] allowing for tentative identification of each compound in SusDat as a combination of its exact mass, MS/MS fragments and the predicted RTI value, reduces the number of false positives in suspect screening.

Thanks to all the above-mentioned interconnected tools, DSFP can provide reliable qualitative and semiquantitative data on the occurrence of already identified as well as novel CECs, thereby providing exhaustive insight into the spatial and temporal distribution of contaminant mixtures in the environment, making NORMAN DSFP a virtual environmental observatory on chemical contamination. Extensions of DSFP for additional chemicals captured in SusDat (e.g. highly polar molecules and gas chromatography-only amenable substances) are under way.

Collaborative European framework to improve data quality and comparability: development and harmonisation of methods

Perspectives and recommendations

Build the capacity of laboratories in Europe and globally by systematic organisation of international Collaborative
Trials addressing analysis of CECs in various matrices by novel analytical technologies.

Pursue progressive testing and implementation of novel sampling and analytical methodologies to help design smart(er) monitoring strategies that can be applied in regulatory monitoring activities.

\section{Rationale}

NORMAN brings together the leading European institutions in the development and harmonisation of measurement methods for the detection of emerging chemicals in the environment. The studies organised by the network represent a crucial step for the scientific community and for environmental agencies for validation and harmonisation of innovative sampling and monitoring tools before their possible future implementation in regulations.

NORMAN is the author of the first common framework for validation of chemical and biological monitoring methods-a protocol which is now adopted as a Technical Specification (TS) of the European Committee for Standardization (CEN) (CEN TS 16800:2015) [36, 37].

More than 15 collaborative trials have been organised by NORMAN since 2006 on a wide range of methods, including non-target screening in water [38], sediment [39], indoor dust [40] and biota [41], in vitro and in vivo bioassays [42] and passive sampling [43, 44]. They have tackled aspects relevant to monitoring and early warning of CECs in the environment and approaches to hazard assessment, including integration of effect-based methods with chemical analysis to improve interpretation of cause-effect links. These trials included not only the assessment of sample preparation and instrumental performance, but also the evaluation of the impact that computational and data processing tools have on interpretation of results.

\section{Advanced data analysis tools: towards a European Early Warning System}

Prioritisation of substances and priority setting Perspectives and recommendations

Systematically collect wide-scope target, suspect and non-target screening data at European scale to improve the spatial and temporal coverage and range of matrices available for risk assessment.

Identify compounds for which robust (eco)toxicity studies are needed as a priority.

Prioritise chemicals for which standards or mass spectra will be required from industry, to enable their detection in the environment.

Develop dynamic open-access links to spatially detailed information about production, uses, exposure to and consumption of chemicals. 
Develop a common European scheme for grouping of chemicals and indicator substances, based on various criteria including sector of use, chemical structure and mode of action.

Integrate more strongly chemical analytical and effectbased methods in order to identify effect and (mixture-) risk drivers, i.e. substances or groups of substances that should be selected for further risk assessment.

\section{Rationale}

In the past decade, NORMAN has developed an integrated strategy to deal with less-investigated substances for which knowledge gaps are identified (e.g. insufficient information on the exposure levels and/or adverse effects, or inadequate performance of the analytical methods for their measurement in the environment) [45]. The concept involves the application of a decision tree which allows the allocation of substances into six main action categories, based on the identified knowledge gaps and actions needed to address them. The priority within each category is then evaluated on the basis of specific occurrence, hazard (persistence, bioaccumulation, mobility, endocrine disruption potential, etc.) and risk indicators such as the Frequency of Exceedance (FoE) and Extent of Exceedance (EoE) of the Lowest PNECs.

Various aspects of a categorisation/ranking system have been scaled up and tested in numerous large-scale European projects and national prioritisation processes such as defining Water Framework Directive (WFD) River Basin Specific Pollutants (RBSP) in the Danube River Basin [46] or selecting national Watch List substances and RBSP in France $[47,48]$ and in The Netherlands [49]. In this way, NORMAN aims to provide a scheme for harmonised RBSP assessment across the EU. On a regular basis, NORMAN also makes recommendations to the Commission regarding substances to be added to the list of WFD Priority Substances and EU Watch List [50].

This workflow, originally designed to work with target monitoring data, now integrates the automatic query of NTS mass spectral information archived in DSFP (see above). Thanks to DSFP and the set of fully integrated tools and databases developed by NORMAN, it is now possible to obtain an overview of the state of knowledge (spatial distribution of contaminants, degree of exceedance of threshold values based on semi-quantified data, etc.) of a dynamically updated list of $>60,000$ chemicals, including many never studied before, and to identify priority substances/groups of substances for which further actions need to be taken.

This approach fits well with the requirements of an Early Warning System, where the data to correctly identify an emerging risk at an early stage are typically limited or of poor quality. In this context, it is important to use a transparent and rational approach for signal identification and characterisation that is able to deal with the knowledge gaps that still prevent proper risk assessment and risk ranking of most emerging substances. Individual components of the Early Warning System concept, such as NormaNEWS, have already been trialled [51].

\section{Effect-based methods (EBM) for monitoring of chemical mixtures in the environment Perspectives and recommendations}

Systematically include NTS and EBM in investigative monitoring programmes to support chemicals risk assessment.

Further develop and implement effect-based methods in a wider range of environmental compartments, including the marine and terrestrial environments.

Harmonise, and provide training on, the use of effectbased methods.

\section{Rationale}

Bioassays are the only currently available methods able to respond to the recently recognised need to address unknown mixture risks present in the environment, which can then be linked to specific chemical compounds via chemical analysis $[52,53]$.

NORMAN is actively contributing to the construction of a common position of the European experts on the use of bioassays in the regulatory framework of the WFD, in particular with the definition of a battery of bioassays for chemical water quality assessment [54]. Besides an interlaboratory study organised in 2009 to assess the comparability of results obtained with a battery of bioassays [42] and a comprehensive literature review on the development of an ecotoxicological perspective on neurotoxicity assessment [55], NORMAN contributed to the Science to Policy Interface (SPI) Estrogen monitoring project (a voluntary initiative of 12 countries and 24 organisations in Europe), which has recently provided concrete demonstration data about the performance of the tested EBM [56].

In terms of practical implementation of EBMs in the regulation, another crucial step is the determination of effect-based trigger values (EBT), which define the acceptable level of effect for each toxicological endpoint of concern and thus allow environmental managers to interpret EBM data and distinguish between more and less polluted sites. In collaboration with the SOLUTIONS project (FP7/603437), NORMAN has contributed to the drafting of a proposal for a harmonised methodology for the definition of effect-based trigger (EBT) values [57] and the way to proceed when an EBT is exceeded [58, 59]. 
In contrast to EQSs, EBTs consider all chemicals in a mixture contributing to a measured effect in a given sample. Explaining the observed activity detected by the applied bioassays and addressing the combined effect of chemicals can be done (using mass balances/'iceberg modelling') by calculation of Toxic Units (TU) for each of the quantified pollutants or Bioanalytical Equivalent concentrations (BEQ), depending on the bioassay. This should be followed by a comparison of the estimated $\sum \mathrm{TU}$ or BEQ from the component-based assessment with the TU and BEQ derived from the bioassay testing. If EBTs are exceeded and the component-based assessment cannot explain the activity detected in the bioassay, an Effect-Directed Analysis (EDA) protocol should be performed in order to identify the risk drivers [54, 60, 61].

In this context, NTS-based approaches are key to improving the identification of risk drivers and facilitating compound/mixture prioritisation in different matrices. As a matter of fact, large datasets from non-target screening and effect-based methods can be explored using multivariate statistics and pattern recognition methods to identify peaks that co-vary with detected effects (virtual effect-directed analysis). The NORMAN Joint Programme of Activities promotes this type of study as a way to identify candidate compounds for further investigation [41].

Finally, as part of its latest Joint Programme of Activities, NORMAN will develop a bioactivity database. This project aims to support the interpretation of effect-based monitoring data for mixture toxicity modelling. A richer set of bioactivity data will be crucial to understanding the contribution of detected chemicals to the observed effect in the different assays. Currently, the lack of effect data for the detected chemicals in different assays is a major limitation and more data is needed for a significant improvement of mixture modelling and elucidation of drivers of toxicity. This database will be essential to reveal CEC-induced bioassay activity that cannot be explained by the measured concentrations of the few individual chemicals for which effect data are already known [41]. Other needs and purposes for this database, e.g. selection of EBMs, are currently being explored within the NORMAN network.

\section{Support to national and European chemical risk assessment: harnessing, combining and sharing evidence and expertise on CECs \\ Cross-border cooperation and information exchange- monitoring super-sites in Europe \\ Perspectives and recommendations}

Organise Europe-wide collaborative environmental monitoring programmes using novel analytical methodologies in a broad range of matrices and on selected super-sites providing representative geographical coverage and results directly supporting regulations.

Improve the sharing and use of local, regional, national and EU-level monitoring data between countries and policy areas (e.g. legislation for environment, chemicals, food, products, waste, etc.) and relevant institutions.

\section{Rationale}

All state-of-the-art tools presented here have been developed and tested within large-scale European projects (e.g. FP7 SOLUTIONS, EDA-EMERGE FP7-PEOPLE-2011-ITN/290100, ANSWER H2020MSCA-ITN-2015/675530, NEREUS COST Action ES1403, APEX LIFE17 ENV/SK/000355).

NORMAN works in close cooperation with international river basin organisations (e.g. the International Commission for the Protection of the Danube River $(\mathrm{ICPDR}) \pm 14$ European countries and the EU; organising Joint Danube Surveys every 6 years), sea conventions (e.g. Black Sea Commission; OSPAR), environmental specimen banks and environmental authorities in various Member States (e.g. France, Germany, Nordic countries, The Netherlands).

In 2019 the NORMAN Association received funding from the ICPDR as a contribution in support of its participation in the experimental activities of the 4th Joint Danube Survey (JDS4). The added value of this type of collaboration is the opportunity to investigate and demonstrate the capabilities and limits of new environmental assessment frameworks with a clear link to their application in a regulatory framework.

So far, NORMAN has been strongly involved in issues related to CECs in the fresh water cycle and the associated EU policies. In the light of NORMAN's missions and the need to ensure a holistic view of emerging risks associated with chemicals in the environment, the activities are progressively being extended to the indoor, marine and terrestrial environment and water reuse, thereby building on experience gained in the water compartment to facilitate the transfer to other environmental matrices.

\section{Conclusions}

Scientific knowledge continues to progress, and novel tools are constantly being developed. This helps competent authorities and industry in the full value chain of chemicals to provide answers to unanswered or newly arising questions regarding risks of chemicals to the environment and human health, with a particular focus on early warning, anticipation and prevention of future risks.

In this paper, we have sought to provide a clear and transparent message about how NORMAN as an 
independent, well-established and competent network of expert organisations in the field of emerging substances has enormous potential to contribute to the implementation of the PARC partnership by sharing several of its existing key tools that we believe are particularly relevant to the success of the initiative.

An important role of the PARC partnership will be to foster cooperation and better use of existing knowledge, for better coordination of research and uptake of scientific findings in regulation.

NORMAN stands ready to provide expert advice to PARC's stakeholder forum, drawing on its 15 years of experience in the development, harmonisation and testing of advanced tools in relation to CECs and in support of a European Early Warning System to unravel the risks of CECs and close the gap between research and innovation and regulatory processes. NORMAN is a platform for scientific cooperation building upon voluntary member contributions to advance our knowledge and understanding of CECs in the environment. By combining the extensive knowledge and experience of the NORMAN network with the financial and policy-related strengths of the PARC initiative, a large step towards the goal of a non-toxic environment can be taken.

\section{Abbreviations}

ARB: antibiotic-resistant bacteria; ARG: antibiotic-resistant genes; BCF: bioconcentration factor; CAS: chemical Abstracts Service; CEC: contaminants of emerging concern; CEN: European Committee for Standardization; CEN TS: CEN Technical Specifications; CIS: Common Implementation Strategy of the WFD; DG ENV: Directorate-General for Environment of the European Commission; DG Research: Directorate General for Research and Innovation of the European Commission; EBM: effect-based methods; EBT: effect-based trigger values; EC: European Commission; ECHA: European Chemical Agency; EC JRC: Joint Research Centre of the European Commission; EDA: effect-directed analysis; EEA: European Environment Agency; EQS: environmental quality standard; ICPDR: International Commission for the Protection of the Danube River; IPCHEM: European Information Platform for Chemical Monitoring; JDS: Joint Danube Survey; NTS: non-target screening; PNEC: predicted no-effect concentration; RBSP: River Basin Specific Pollutants; WFD: Water Framework Directive.
\end{abstract}

\section{Acknowledgements}

The NORMAN Association gratefully acknowledge the support of all their members and collaborators over the 15 years of the association.

\section{Authors' contributions}

VD, JK and JS have closely collaborated to write the first draft manuscript. PvdO, ES and TS provided detailed feedback/material on specific activities. All authors have read, made comments and approved the final manuscript.

\section{Funding}

Not applicable.

\section{Availability of data and materials}

Not applicable.

Ethics approval and consent to participate

Not applicable.
Consent for publication

Not applicable.

\section{Competing interests}

The authors declare that they have no competing interests.

\section{Author details}

${ }^{1}$ INERIS, National Institute for Environment and Industrial Risks, Verneuil en Halatte, France. ${ }^{2}$ UBA, Federal Environment Agency, Dessau-Roßlau, Germany. ${ }^{3}$ NIVA, Norwegian Institute for Water Research, Oslo, Norway. ${ }^{4}$ Wageningen University \& Research, Wageningen, The Netherlands. ${ }^{5}$ Eawag, Dübendorf, Switzerland. ${ }^{6}$ IVL, Swedish Environmental Research Institute, Goteborg, Sweden. ${ }^{7}$ NILU, Norwegian Institute for Air Research, Kjeller, Norway. ${ }^{8}$ Environmental Institute, Koš, Slovakia. ${ }^{9}$ Department of Environmental Science, Stockholm University, Stockholm, Sweden. ${ }^{10}$ Department of Aquatic Sciences and Assessment, SLU, Swedish University of Agricultural Sciences, Uppsala, Sweden. ${ }^{11}$ National and Kapodistrian University of Athens, Athens, Greece. ${ }^{12}$ CSIC, Spanish Council for Scientific Research, Barcelona, Spain. ${ }^{13}$ DCE, Aarhus University, Aarhus, Denmark. ${ }^{14}$ UFZ, Helmholtz Centre for Environmental Research, Leipzig, Germany. ${ }^{15}$ Goethe University, Frankfurt am Main, Germany. ${ }^{16}$ Leesu Ecole des Ponts, Univ Paris Est Creteil, Marne-la-Vallee, France. ${ }_{17}$ Department of Plant and Environmental Sciences, University of Copenhagen, Copenhagen, Denmark. ${ }^{18}$ Toxicological Centre, University of Antwerp, Wilrijk, Belgium. ${ }^{19} \mathrm{AD}$ eco advies, Amsterdam, The Netherlands. ${ }^{20}$ DERACEnvironmental risk assessment of chemicals, Marseille, France. ${ }^{21}$ KWRWater Research Institute, Nieuwegein, The Netherlands. ${ }^{22}$ Institute for Risk Assessment Sciences, Utrecht University, Nieuwegein, The Netherlands. ${ }^{23}$ SWACCS, Swedish Academic Consortia for Chemical Safety, Örebro, Sweden. ${ }^{24}$ MTM Research Centre, Örebro University, Örebro, Sweden. ${ }^{25}$ Department of Civil and Environmental Engineering and Nireas-International Research Center, University of Cyprus, Nicosia, Cyprus. ${ }^{26}$ ICRA, Catalan Institute for Water Research, Girona, Spain. ${ }^{27}$ University Jaume I, Castellón, Spain. ${ }^{28}$ Faculty of Science, Centre RECETOX, Masaryk University, Brno, Czech Republic. ${ }^{29}$ Ecotox Centre Eawag, Dübendorf, Switzerland. ${ }^{30}$ Department of Chemistry, University of Bath, London, UK. ${ }^{31}$ Department of Chemistry, Aristotle University of Thessaloniki, Thessaloniki, Greece. ${ }^{32}$ Vrije Universiteit Amsterdam, Amsterdam, The Netherlands. ${ }^{33}$ BRGM, Orléans, France. ${ }^{34}$ Lulea Technical University, Lulea, Sweden. ${ }^{35}$ VúVH, Water Research Institute, Bratislava, Slovakia. ${ }^{36}$ Plentzia Marine Station-Univ Basque Country (PiE-UPV/EHU), Plentzia, Basque Country, Spain. ${ }^{37}$ Marine Institute, Galway, Ireland. ${ }^{38}$ INRAE, Ur Riverly, Lyon, France. ${ }^{39}$ The Environmental Protection Agency Ireland, Dublin, Ireland. ${ }^{40}$ SYKE, Finnish Environment Institute, Helsinki, Finland. ${ }^{41}$ IRSA-CNR, Water Research Institute, Brugherio, Italy. ${ }^{42}$ RIVM, Centre for Sustainability, Environment and Health, Bilthoven, The Netherlands. ${ }^{43}$ Department of Environmental Science, Radboud University Nijmegen, Nijmegen, The Netherlands. ${ }^{44}$ Fraunhofer Institute for Molecular Biology and Applied Ecology IME-AE, Schmallenberg, Germany. ${ }^{45}$ University of Amsterdam, Amsterdam, The Netherlands. ${ }^{46}$ LCSB, University of Luxembourg, Belvaux, Luxembourg. ${ }^{47}$ LfU, Bavarian Environment Agency, Augsburg, Germany. ${ }^{48}$ RWS, Ministry of Infrastructure and the Environment, Nijmegen, The Netherlands. ${ }^{49}$ Department of Environmental Science, Aarhus University, Aarhus, Denmark. ${ }^{50}$ Middlesex University, London, UK.

Received: 31 May 2020 Accepted: 6 July 2020

Published online: 20 July 2020

\section{References}

1. European Commission: Candidates for European Partnerships, European Partnership for Chemicals Risk Assessment. https://ec.europa.eu/info/files /european-partnership-chemicals-risk-assessment_en. Accessed 20 June 2020

2. European Commission: The European Green Deal-COM (2019) 640 final. 2019

3. Council of the European Union: Towards a Sustainable Chemicals Policy Strategy of the Union—Council conclusions. (2019) http://data.consilium. europa.eu/doc/document/ST-10713-2019-INIT/en/pdf. Accessed 20 May 2020

4. Council of the European Union: The 8th Environment Action Programme-Turning the Trends Together-Council conclusions (2019) 
https://www.consilium.europa.eu/media/40927/st12795-2019.pdf. Accessed 20 May 2020

5. Committee of Combination of effects and assessing chemicals in groups: future chemical risk management-Accounting for combination effects and assessing chemicals in groups (2019) In: Swedish Government Official Reports (SOU). Edited by Reports SGO

6. Dulio V, Bavel B, Brorström-Lundén E, Harmsen J, Hollender J, Schlabach M, Slobodnik J, Thomas K, Koschorreck J (2018) Emerging pollutants in the EU: 10 years of NORMAN in support of environmental policies and regulations. Environ Sci Eur 30:23

7. NORMAN Network: List of NORMAN members. https://www.normandata eu/?q=node/199. Accessed 20 May 2020

8. Comero S, Dalla Costa S, Cusinato A, Korytar P, Kephalopoulos S, Bopp S, Gawlik BM (2020) A conceptual data quality framework for IPCHEM-The European Commission Information Platform for chemical monitoring. TrAC Trends Anal Chem 127:115879

9. Kephalopoulos S, Bopp SK, Costa SD, Cusinato A, Lipsa D, Geiss O (2020) Indoor air monitoring: sharing and accessing data via the Information Platform for chemical monitoring (IPCHEM). Int J Hyg Environ Health 227:113515

10. NORMAN Network: NORMAN Database System. https://www.norma n-network.com/nds/. Accessed 20 May 2020

11. Slobodnik J, Hollender J, Schulze T, Schymanski EL, Brack W (2019) Establish data infrastructure to compile and exchange environmental screening data on a European scale. Environ Sci Eur 31 (1):65

12. NORMAN Network: NORMAN Suspect List Exchange. https://www.norma n-network.com/nds/SLE/. Accessed 20 May 2020

13. NORMAN Network: NORMAN Substance Database (SusDat). https://www. norman-network.com/nds/susdat/. Accessed 20 May 2020

14. EPA U: Chemistry Dashboard-list of Chemicals. https://comptox.epa.gov/ dashboard/chemical_lists/?search=NORMAN. Accessed 20 May 2020

15. Williams AJ, Grulke CM, Edwards J, McEachran AD, Mansouri K, Baker NC, Patlewicz G, Shah I, Wambaugh JF, Judson RS et al (2017) The CompTox chemistry dashboard: a community data resource for environmental chemistry. J Cheminform 9:61

16. Kim S, Chen J, Cheng T, Gindulyte A, He J, He S, Li Q, Shoemaker BA, Thiessen PA, Yu B et al (2019) PubChem 2019 update: improved access to chemical data. Nucleic Acids Res 47(D1):D1 102-D1109

17. PubChem: NORMAN Suspect List Exchange. https://pubchem.ncbi.nlm. nih.gov/source/23819. Accessed 20 May 2020

18. Zenodo: NORMAN Suspect List Exchange. https://zenodo.org/commu nities/norman-sle?page $=1 \&$ size $=20$. Accessed 20 May 2020

19. McEachran AD, Mansouri K, Grulke C, Schymanski EL, Ruttkies C, Williams AJ (2018) "MS-Ready" structures for non-targeted high-resolution mass spectrometry screening studies. J Cheminform 10(1):45

20. Norman Network: NORMAN Ecotoxicology Database. https://www.norma n-network.com/nds/ecotox/. Accessed 20 May 2020

21. Moermond CT, Kase R, Korkaric M, Ágerstrand M (2016) CRED: criteria for reporting and evaluating ecotoxicity data. Environ Toxicol Chem 35(5):1297-1309

22. European Commission (2011) WFD-CIS Guidance document No. 27 Technical guidance on deriving Environmental Quality Standards, Technical report 2011-055

23. Aalizadeh R, von der Ohe PC, Thomaidis NS (2017) Prediction of acute toxicity of emerging contaminants on the water flea Daphnia magna by Ant Colony Optimization-Support Vector Machine QSTR models. Environ Sci 19(3):438-448

24. NORMAN Network: NORMAN EMPODAT Database-Chemical Occurrence Data. https://www.norman-network.com/nds/empodat/. Accessed 20 May 2020

25. Hollender J, van Bavel B, Dulio V, Farmen E, Furtmann K, Koschorreck J, Kunkel U, Krauss M, Munthe J, Schlabach M et al (2019) High resolution mass spectrometry-based non-target screening can support regulatory environmental monitoring and chemicals management. Environ Sci Eur 31(1):42

26. Alygizakis NA, Oswald P, Thomaidis NS, Schymanski EL, Aalizadeh R, Schulze T, Oswaldova M, Slobodnik J (2019) NORMAN digital sample freezing platform: a European virtual platform to exchange liquid chromatography high resolution-mass spectrometry data and screen suspects in "digitally frozen" environmental samples. TrAC Trends Anal Chem 115:129-137
27. MassBank Europe: MassBank Europe: High Quality Mass Spectral Database. https://massbank.eu//MassBank/. Accessed 20 May 2020

28. Schymanski E, Jeon J, Gulde R, Fenner K, Ruff M (2014) Identifying small molecules via high resolution mass spectrometry: communicating confidence. Environ Sci Technol 48:4

29. Zenodo: MassBank/MassBank-data: Release version 2020.05. https:// zenodo.org/record/3786381\#.XsBXPcQ6_IU. Accessed 20 May 2020

30. Oberacher H, Sasse M, Antignac J-P, Guitton Y, Debrauwer L, Jamin EL, Schulze T, Krauss M, Covaci A, Caballero-Casero N et al (2020) A European proposal for quality control and quality assurance of tandem mass spectral libraries. Environ Sci Eur 32(1):43

31. Elixir: ELIXIR Metabolomics Community. https://elixir-europe.org/commu nities/metabolomics. Accessed 20 May 2020

32. deNBI: German Network for Bioinformatics Infrastructure Service, Training Cooperations \& Cloud Computing. https://www.denbi.de/. Accessed 20 May 2020

33. NFDI4Chem: Chemistry Consortium in the National Research Data Infrastructure (NFDI). https://www.nfdi4chem.de/. Accessed 20 May 2020

34. Aalizadeh R, Nika M-C, Thomaidis NS (2019) Development and application of retention time prediction models in the suspect and non-target screening of emerging contaminants. J Hazard Mater 363:277-285

35. Aalizadeh R (2019) Retention Time Indices Platform. http://rti.chem.uoa. $\mathrm{gr} /$. Accessed 19 May 2020'

36. CEN/TC 230: CEN/TS 16800:2015-Guideline for the validation of physico-chemical analytical methods. 2015. https://www.en-standard. eu/pd-cen-ts-16800-2015-guideline-for-the-validation-of-physico-chemi cal-analytical-methods/. Accessed 20 May 2020

37. Schwesig D, Borchers U, Chancerelle L, Dulio V, Eriksson U, Farré M, Goksoyr A, Lamoree M, Leonards P, Wegener J-W (2011) A harmonized European framework for method validation to support research on emerging pollutants. TrAC Trends Anal Chem 30:8

38. Schymanski EL, Singer HP, Slobodnik J, Ipolyi IM, Oswald P, Krauss M, Schulze T, Haglund P, Letzel T, Grosse S (2015) Non-target screening with high-resolution mass spectrometry: critical review using a collaborative trial on water analysis. Anal Bioanal Chem 407:12

39. Brandsma SH, de Boer J, Leonards PEG, Cofino WP, Covaci A, Leonards PEG (2013) Organophosphorus flame-retardant and plasticizer analysis, including recommendations from the first worldwide interlaboratory study. TrAC Trends Anal Chem 43:217-228

40. Rostkowski $\mathrm{P}$, Haglund $\mathrm{P}$, Aalizadeh R, Alygizakis N, Thomaidis N, Arandes JB, Nizzetto PB, Booij P, Budzinski H, Brunswick P et al (2019) The strength in numbers: comprehensive characterization of house dust using complementary mass spectrometric techniques. Anal Bioanal Chem 411(10):1957-1977

41. NORMAN Network: NORMAN Joint Programme of Activities 2020 (JPA 2020). https://www.norman-network.net/sites/default/files/files_priva te/JointProgramme2020/NORMAN\%20JPA\%202020_Final_Feb2020.pdf. Accessed 20 May 2020

42. Di Paolo C, Ottermanns R, Keiter S, Ait-Aissa S, Bluhm K, Brack W, Breitholtz M, Buchinger S, Carere M, Chalon C et al (2016) Bioassay battery interlaboratory investigation of emerging contaminants in spiked water extracts - towards the implementation of bioanalytical monitoring tools in water quality assessment and monitoring. Water Res 104:473-484

43. Miège C, Mazzella N, Allan I, Dulio V, Smedes F, Tixier C, Vermeirssen E, Brant J, O'Toole S, Budzinski H et al (2015) Position paper on passive sampling techniques for the monitoring of contaminants in the aquatic environment-achievements to date and perspectives. Trends Environ Anal Chem 8(1):20-26

44. Vrana B, Smedes F, Roman P, Loos R, Nicolas M, Miège C, Budzinski H, Vermeirssen E, Ocelka T, Gravell A et al (2016) NORMAN Interlaboratory Study on passive sampling of emerging pollutants, Chemical Monitoring On Site (CM Onsite) organised by the NORMAN Association and European DG Joint Research Centre (JRC) in support of the Common Implementation Strategy (CIS) of the Water Framework Directive (WFD)). JRC97181

45. Dulio V, von der Ohe PC (2013) NORMAN Prioritisation framework for emerging substances: ISBN: 978-2-9545254-0-2

46. ICPDR-International Commission for the Protection of the Danube River: River Basin Management Plan (2015) https://www.icpdr.org/main/activ ities-projects/river-basin-management-plan-update-2015. Accessed 20 May 2020 
47. Botta F, Dulio V, Andres S, Feray C, Morin A: NORMAN Network Bulletin 2012. A watch list of emerging pollutants for surface water monitoring in France. https://www.norman-network.net/sites/default/files/files/bulle tins/newsletter_norman_3a-r.pdf. Accessed 20 June 2020

48. Lopez B, Ghestem JP, Bonneville S (2018) Selection and prioritization of substances to be regulatory monitored in groundwater under the WFD. La Houille Blanche 3:10-17

49. Ministry of Infrastructure and Water Management: Water Management in The Netherlands (2019)

50. European Union: Commission Implementing Decision (EU) 2018/840 of 5 June 2018 establishing a watch list of substances for Union-wide monitoring in the field of water policy pursuant to Directive 2008/105/EC of the European Parliament and of the Council and repealing Commission Implementing Decision (EU) 2015/495 (notified under document C(2018) 3362) (2018) In.: OJ L 141, 7.6.2018. pp 9-12

51. Alygizakis NA, Samanipour S, Hollender J, Ibanez M, Kaserzon S, Kokkali V, van Leerdam JA, Mueller JF, Pijnappels M, Reid MJ et al (2018) Exploring the potential of a global emerging contaminant early warning network through the use of retrospective suspect screening with high-resolution mass spectrometry. Environ Sci Technol 52(9):5135-5144

52. Brack W, Dulio V, Ågerstrand M, Allan I, Altenburger R, Brinkmann M, Bunke D, Burgess RM, Cousins I, Escher Bl et al (2017) Towards the review of the European Union Water Framework Directive: recommendations for more efficient assessment and management of chemical contamination in European surface water resources. Sci Total Environ 576:720-737

53. Escher BI, Stapleton HM, Schymanski EL (2020) Tracking complex mixtures of chemicals in our changing environment. Science (New York, NY) 367(6476):388-392

54. Brack W, Aissa SA, Backhaus T, Dulio V, Escher BI, Faust M, Hilscherova K, Hollender J, Hollert H, Müller C et al (2019) Effect-based methods are key. The European Collaborative Project SOLUTIONS recommends integrating effect-based methods for diagnosis and monitoring of water quality. Environ Sci Eur 31(1):10

55. Legradi JB, Di Paolo C, Kraak MHS, van der Geest HG, Schymanski EL, Williams AJ, Dingemans MML, Massei R, Brack W, Cousin X et al (2018)
An ecotoxicological view on neurotoxicity assessment. Environ Sci Eur 30(1):46

56. Könemann S (2018) Effect-based and chemical analytical methods to monitor estrogens under the European water framework directive. TrAC Trends Anal Chem 102:76

57. Escher BI, Aït-Aïssa S, Behnisch PA, Brack W, Brion F, Brouwer A, Buchinger S, Crawford SE, Du Pasquier D, Hamers T et al (2018) Effect-based trigger values for in vitro and in vivo bioassays performed on surface water extracts supporting the environmental quality standards (EQS) of the European Water Framework Directive. Sci Total Environ 628-629:748-765

58. NORMAN and Water Europe: Joint NORMAN and Water Europe Position Paper, Contaminants of Emerging Concern in Urban Wastewater (2019) https://www.normandata.eu/sites/default/files/files/Publications/Posit ion\%20paper_CECs\%20UWW_NORMAN_WE_2019_Final_20190910_ public.pdf. Accessed 20 May 2020

59. Deviller G, Lundy L, Fatta-Kassinos D (2020) Recommendations to derive quality standards for chemical pollutants in reclaimed water intended for reuse in agricultural irrigation. Chemosphere 240:124911

60. König M, Escher BI, Neale PA, Krauss M, Hilscherová K, Novák J, Teodorović I, Schulze T, Seidensticker S, Kamal Hashmi MA et al (2017) Impact of untreated wastewater on a major European river evaluated with a combination of in vitro bioassays and chemical analysis. Environ Pollut 220:1220-1230

61. Neale PA, Ait-Aissa S, Brack W, Creusot N, Denison MS, Deutschmann B, Hilscherová K, Hollert H, Krauss M, Novák J et al (2015) Linking in vitro effects and detected organic micropollutants in surface water using mixture-toxicity modeling. Environ Sci Technol 49(24):14614-14624

\section{Publisher's Note}

Springer Nature remains neutral with regard to jurisdictional claims in published maps and institutional affiliations.

\section{Submit your manuscript to a SpringerOpen ${ }^{\circ}$ journal and benefit from:}

- Convenient online submission

- Rigorous peer review

- Open access: articles freely available online

- High visibility within the field

- Retaining the copyright to your article

Submit your next manuscript at $\boldsymbol{\nabla}$ springeropen.com 